\title{
Detection of Salmonella infection in slaughter cattle using meat juice and serum
}

\author{
Abdulkadir A. ${ }^{*}$, Adamu N. A., Bitrus S., Gana L. L., Habibu S., Mohammed Y. Y., Alao E. A. \\ and Mohammed F. I.
}

Department of Animal Health, College of Agriculture and Animal Science, Mando: Division of Agricultural Colleges, Ahmadu Bello University, Zaria, Nigeria.

${ }^{*}$ Corresponding author. Email: bdlkdr_1@yahoo.com.

Copyright (@ 2016 Abdulkadir et al. This article remains permanently open access under the terms of the Creative Commons Attribution License 4.0, which permits unrestricted use, distribution, and reproduction in any medium, provided the original work is properly cited.

Received 26th January, 2016; Accepted 27th February, 2016

\begin{abstract}
Monitoring for Salmonella in slaughter cattle is important to enable targeted control measures to be applied on problem farms and at the abattoir. The aim of this study was to determine whether meat juice could be used as much as serum to identify slaughter cattle with a high prevalence of infection. Samples of meat juice \& serum were taken from 100 slaughter cattle and comparisons were made between the results of individual Enzyme-linked immunosorbent assay (ELISA) tests on serum and meat juice. The ELISA tests showed a statistically significant Serum mean optical density (O.D.) with meat juice mean optical density (O.D.) from seven animals. All but one of the seven positive individual sample serum O.D. and sample/positive control $(S / P)$ ratio results correlated significantly with the results of the meat juice O.D. ELISA. The results show a generally good correlation between serological results of individual serum and meat juice samples in slaughter cattle. Thus, ELISA could be used to flag up potentially hazardous Salmonella contaminated meat from slaughter cattle or herds which are more likely to be in need of improved Salmonella control. This can then be confirmed by bacteriological sampling at the abattoir or farm level and a control plan imposed.
\end{abstract}

Key words: Enzyme-linked immunosorbent assay; meat juice; slaughter cattle; Salmonella; serum; test sample correlation.

\section{INTRODUCTION}

Salmonella is a genus of bacteria that are a major cause of foodborne outbreaks in humans throughout the world (Waldvogel, 2000; Hirose et al., 2001). Due to genetic and environmental diversity Salmonella serotypes are adapted to live in a various range of hosts and habitats using pathogenic and non-pathogenic means of surviving (Callaway, et al, 2008). The prevalence of this pathogen presents major challenges in the food production and public health sectors in their efforts to supply safe foods as consumers' food safety awareness is also on the increase.

Salmonella is a cause of acute and subclinical disease in cattle (Wray and Davies, 2000). It can cause disease in cattle of all ages, though the most commonly clinically affected group is calves aged 2 weeks to 3 months
(Nielsen, 2003). Salmonella infections are still one of the most important foodborne diseases in humans and beef is one of the major sources for Salmonella infections in humans (Hutwagner et al., 1997). The Salmonellae bacteria are generally transmitted to humans through consumption of mainly contaminated food of animal origin like beef and milk (Mead et al., 1999). Animals may also become infected from other Salmonella infected animals, directly or via a contaminated environment, including contaminated feed (European Food Safety Authority, 2011). Septicaemic cases due to Salmonella typhi are being reported in Africa especially in Kenya and Ghana (Mills-Robertson et al., 2002; Kariuki et al., 2004).

The importance of cattle as vectors of Salmonella have been shown by several abattoir studies where the 
prevalence of Salmonella in cattle caecal samples collected was high (8.34\%) in Sango-Ota, Nigeria, and low for cattle and sheep (1.4\% and $1.1 \%$ respectively) in Great Britain (Milnes, 2007). Infection in cattle can cause a range of clinical signs, from scouring to fever and death, but is often sub-clinical and so, is difficult for farmers to monitor and detect. Although it is unknown how many cases of human salmonellosis are attributed to eating cattle products, most cases are suspected to be related to the serovars $S$. Typhimurium, S. Dublin, $S$. Typhi, S. Paratyphi, and S. Newport which are all predominant types detected in samples from cattle (DEFRA, 2007). In the cattle industry, Salmonella Dublin causes economic losses in the form of death among calves and young animals, abortions and reproductive disorders among adult cattle, extra labor and increased veterinary expenses (Liza and Annette, 2004).

The starting point for control is monitoring to define the extent and distribution of infection. Bacteriological monitoring gives the best indication of the distribution of Salmonella on farms and facilitates the introduction and monitoring of control measures (Bager and Baggesen, 1993), but this must be carried out sufficiently rigorously to be meaningful, which may be expensive. Serological testing is less expensive for each individual sample, whereas bacteriological samples can be pooled. Pooled bacteriological samples have been very effective for monitoring large groups of poultry (Kradel and Miller, 1991; Aho, 1992), but are more difficult to achieve in a representative way for routine use on cattle farms/herds. Serology may provide a more sensitive indication of persistent cattle herd infection than limited bacteriology (Wiuff et al., 2002).

Many studies have tried to ascertain the factors that influence Salmonella prevalence, and identify on-farm control measures to reduce the Salmonella burden in livestock. Controlling Salmonella infections in cattle herds can provide economic, health and welfare benefits in the cattle industry, and may reduce the zoonotic risk. Risk factor identification is a necessary prerequisite to identifying suitable on-farm control measures to reduce the Salmonella burden, through precise and targeted approach. However, in order to study the infections dynamics within herds and risk factors affecting the spread of the infection, more knowledge about the prevalence for individual animals is required, and approaches for using these test over time and in combination need to be ascertained.

\section{MATERIAL AND METHODS}

The 200 samples were all collected in Kaduna from two abattoirs (Tudun Wada \& Kawo Abattoirs) which were all from the central zone of Kaduna State.

The Tudun Wada Abattoir was established in 1959 by
British colonials. It is the oldest and also the first abattoir in Nigeria to be established. About 200 cattle are slaughtered daily. The Kawo Abattoir was established in 1994. About 200 cattle are slaughtered daily.

This was a cross sectional study involving a systematic random sample of slaughter cattle, $10 \%$ of the daily slaughter cattle was selected and the 10th cattle in the slaughter line were randomly selected for sampling. Thus 20 samples were collected daily. Animals were sampled only after owner's consent was given. Blood and meat of each selected cattle was collected. Blood was collected directly immediately after slaughter in $20 \mathrm{ml}$ sterile sample bottle which were transported in cool boxes to the microbiology/parasitology laboratory of College of Agriculture and Animal Science, Ahmadu Bello University Mando Road, Kaduna. The samples were centrifuged at $1,000 \mathrm{~g}$ for 15 minutes, after which the supernatant (serum) was decanted into sterile serum bottle and was refrigerated at $-20^{\circ} \mathrm{C}$ until further processing. Meat samples were collected form brisket of each selected cattle, wrapped into a sterile polythene bag, placed on ice in a cool box and immediately transported to the microbiology/parasitology laboratory of the College of Agriculture and Animal Science, Ahmadu Bello University, Mando Road, Kaduna. The meat samples were frozen for 24hours after which the samples were removed from the freezer and were kept to thaw into sterile sample bottle for the meat juice. All samples were identified by appropriate labeling.

\section{ELISA test procedure}

The Lipopolysaccharide (LPS) coated plate (Porcine Salmonella Antibody Test Kit; LPS B, C1, \& D combined, BioChek, Burg Bracklaan 57, 2811 BP Reeuwijk. Holland) was removed from scaled bag and location of samples on template was recorded.

$100 \mu 1$ of Negative Control and Positive Control were added into wells A1, B1, C1 and D1. $100 \mu 1$ of diluted samples were added into the appropriate wells and the plates were covered with lid and incubated at room temperature $\left(22-27^{\circ} \mathrm{C}\right)$ for 30 minutes. The contents of wells were aspirated and washed 4 times with wash buffer (300 11 per well). Plates were inverted and tapped firmly on absorbent paper. $100 \mu 1$ of conjugate reagents were added into the appropriate wells. Plates were covered with lid and incubated at room temperature (22$27^{\circ} \mathrm{C}$ ) for 30 minutes. Wash procedure was repeated as earlier described. $100 \mu 1$ of prepared substrate reagents were added into the appropriate wells. Plates were covered with lid and incubated at room temperature 22$27^{\circ} \mathrm{C}$ ) for 15 minutes. $100 \mu 1$ of stop solution were added to the appropriate wells to stop reaction. The micro titer plate was blanked in the air and the absorbance of control and samples was recorded by reading at $405 \mathrm{~nm}$ 
Table 1. ELISA Result Comparison for Serum and Meat Juice

\begin{tabular}{lccccl}
\hline \multirow{2}{*}{ Sample ID } & \multicolumn{2}{c}{ SERUM ELISA } & \multicolumn{2}{c}{ MJ ELISA } & \multirow{2}{*}{ Location } \\
\cline { 2 - 5 } & S/P & OD\% & S/P & OD\% & \\
\hline Kw6 & 0.4 & 10 & 0.92 & 23 & Kawo \\
Kw7 & 0.4 & 10 & 0.88 & 22 & Kawo \\
Kw8 & 0.4 & 10 & 0.76 & 19 & Kawo \\
Kw11 & $0.292^{*}$ & $7.3^{*}$ & 0.52 & 13 & Kawo \\
Tw16 & 0.68 & 17 & 4.8 & 119.8 & Tudun Wada \\
Tw36 & 0.68 & 17 & 3.44 & 86 & Tudun Wada \\
Tw42 & 0.6 & 15 & 1.4 & 35 & Tudun Wada \\
\hline
\end{tabular}

ELISA: enzyme linked immunosorbent assay, MJ: meat juice, S/P; sample o positive ratio, OD: optical density. *Negative result

using an ELISA reader (MC Jefferson KC-100 microplate reader, 4 Dunton Road, SE1 5SJ, London, United Kingdom).

\section{Questionnaire}

A brief questionnaire was administered at the time of sample collection to investigate factors potentially associated with Salmonella in cattle such as source of animal, age, sex, breed, body condition score and previous antimicrobial usage.

\section{Statistical analysis}

Data collected from the study area were analyzed using Chi square test at $95 \%$ confidence interval with values of $\mathrm{P} \leq 0.05$ considered significant. All analysis was done using statistical package for social sciences (SPSS) version 17.0.

\section{RESULT}

A total of 100 duplicate samples (serum and meat juice) were taken from slaughter cattle at the two (2) abattoirs located at Kawo and Tudun Wada, Kaduna metropolis. The animals originate from several sources within Kaduna State; including Anchau, Zaria, Birnin, Gwari, Kasuwan Magani, Kwai, Kauru, and livestock stations adjacent the abattoir (Zango). Sources outside Kaduna State include: Niger, Katsina State, Bauchi State, and Sokoto State. Antibodies against salmonella spp. were detected in 6 serum and 7 meat juice samples $(7 \%, p \leq$ $0.05)$. In all 6 serum samples (100\% of positives) and 2 meat juice samples only low positive results (OD\% $10 \%$ $20 \%$ ) were detected. High positive samples (OD\% > $40 \%)$ were found in 2 samples of meat juice $(15 \%$ of positives) while 3 meat juice samples had OD\% between 20\%-35\% (Table 1). All serum positive samples were also positive with meat juice from same animal. All positive samples were detected only in animals that were sourced or originated from the 'Zango'. All positive samples were also animals aged between 3-6yrs, had a body condition score of 3-5, and were all White Fulani breeds of cattle. Kawo abattoir had a higher prevalence of $4 \%(7 / 200)$ while Tudun Wada abattoir had a prevalence of $3 \%(6 / 200)$.

\section{DISCUSSION}

The ELISA kit used in this survey allows detection of antibodies to a broad range of Salmonella serogroups (B, $C 1$, and $D$ ) indicating the exposure of cattle to the bacterium. The data presented in this study demonstrate the presence of antibodies specific to salmonella spp. In cattle presented for slaughter at the abattoir. About $7 \%$ of the animals tested were positive for antibodies against Salmonella spp., which is an agreement with previous works done on farms (Alao et al., 2012) where a prevalence of $8.28 \%$ was established. Although the individual serum or meat juice Salmonella ELISA test has a poor correlation with bacteriology on an individual basis (Christensen et al., 1999; Clouting and Davies, 2001; Davies et al., 2001; Corre'ge', 2002), this study indicates that infection with Salmonella spp. does not only occur in herds but also in slaughter cattle. So slaughter cattle should be considered as potential source of Salmonella and thus constitute a public health hazard. This approach has been adopted in several other countries worldwide (Ludewig and Fehlhaber, 2001) and in other target species (Hoorfar et al., 1997; Feld et al., 2000; Nollet and Maes, 2005). However, this result cannot be compared to the results from monitoring of herds, which aim to categorize the health status of the herds.

Although in other studies, higher number of livestock collections might indicate that the abattoir have a greater amount of health condition problems, possibly caused by Salmonella or from health conditions associated with Salmonella infection, these factors may also be a risk 
simply because the increased number of vehicles entering the abattoir can facilitate the spread of Salmonella (Pritchard et al., 2005; Beloeil et al., 2007; Shilangale, 2014). No significant risk factor was identified in this study. This may be because only a small number of variables were analyzed and thus more important risk factors may have been missed or the true effect of variables underestimated. However, body condition score (BCS) of 4-5 was identified as a significant risk factor (OR 2.4, Cl; 1.23-2.89). This may be a reflection of risk associated with latent carrier animals, whom look apparently healthy with a good body condition score (BCS) but have either subclinical disease and/or are shading the organism.

\section{Conclusion and Recommendation}

Serological examination provides a powerful tool to monitor infections with salmonella, when the diagnostic cut-off value of the ELISA $>10 \%$ OD is used, and meat juice has proven to be a better sample than serum for serological monitoring/screening of slaughter cattle. This will not only raise awareness of infections with salmonella spp. in cattle, but also provide a basis for effective disease control. The individual serum or meat juice Salmonella ELISA test here has shown an unusual good correlation, hence, it should be used to flag up herds which are more likely to be in need of improved Salmonella control or slaughter cattle that may pose a public health risk. It is also possible to organize logistic slaughter based on herd ELISA result to reduce carcass contamination and thus recommended as a routine procedure for the abattoir to adopt. To decrease the risk from deliveries and visitors, biosecurity measures such as wearing protective clothing and footwear; the routine use of bootdips; ensuring deliveries are only made at the abattoir perimeter, and closing the abattoir to all but essential external vehicles should be utilized.

\section{CONFLICT OF INTEREST}

The authors declare that they have no conflict of interest.

\section{REFERENCES}

Aho, M. (1992) Problems of Salmonella sampling. International Journal of Food Microbiology. 15, 225-235.

Alao F., Kester C., Gbagba, B., \& Fakilede, F. (2012). Comparison of prevalence and antimicrobial sensitivity of Salmonella Typhimurium in apparently healthy cattle and goats in Sango-Ota, Nigeria. The Internet Journal of Microbiology. 10(2). http://ispub.com/ijmb/10/2/14221.

Bager, N. \& Baggesen, D. (1993). The Serological Response to Salmonella Serovar and Infant in Experimentally Infected
Pigs the time Course Followed with an Indirect Ant - LPS ELISA \& Bacteriological Examination. Pp. 205-218

Beloeil, P. A., Chauvin, C., Proux, K., Fablet, C., Madec, F., \& Alioum, A. (2007). Risk factors for Salmonella seroconversion of fattening pigs in farrow-to-finish herds. Veterinary Research. 38, 835-848.

Callaway, T. R., Edrington, T. S., Anderson, R. C., Byrd, J. A. \& Nisbet, D. J. (2008). Gastrointestinal microbial ecology and the safety of our food supply as related to Salmonella. Journal of Animal Science. 86(14), E163-E172.

Christensen, J., Baggesen, D.L., Sørensen, V., \& Svensmark, B. (1999). Salmonella level of swine herds based on serological examination of meat-juice samples and Salmonella occurrence measured by bacteriological follow up. Preventive Veterinary Medicine. 40, 277-292.

Clouting, C., \& Davies, R. H. (2001). Evaluation of the Salmonella meat-juice ELISA in the UK situation. Proceedings of Salinpork 2001. 4th International Symposium on Epidemiology and Control of Salmonella and Other Foodborne Pathogens in Pork. 2-5 September 2001, Leipzig, Germany, pp. 496-498.

Corre'ge', I. (2002). Salmonella in pig farms: characterisation and epidemiological importance of the Salmonella status of gilts. Techni Porc., 25, 13-17.

Davies, R.H., Dalziel, R., Wilesmith, J.M., Ryan, J., Evans, S. J., Paiba, G. A., Byrne, C. \& Pascoe, S. (2001). National survey for Salmonella in pigs at slaughter in Great Britain. Proceedings of Salinpork 2001. 4th International Symposium on Epidemiology and Control of Salmonella and Other Foodborne Pathogens in Pork. 2-5 September 2001, Leipzig, Germany, pp. 162-173.

Feld, N.C., Ekeroth, L., Gradel, K.O., Kabell, S. and Madsen, M. (2000) Evaluation of a serological Salmonella Mix-ELISA for poultry used in a national surveillance programme. Epidemiology and Infection, 125, 263-268.

Department of Environment, Food, and Rural Affairs (DEFRA) (2007). Zoonoses Report United Kingdom, 16-17.

European Food Safety Authority (EFSA) (2011). Analysis of the baseline survey on the prevalence of Campylobacter in broiler batches and of Campylobacter and Salmonella on broiler carcasses in the EU; Part B: Analysis of factors associated with Salmonella contamination of broiler carcasses. EFSA Journal. 9(2), 2017

Hirose, K., Tamura, K., Sagara, H. \& Watnbe, H. (2001). Antibiotic susceptibility of Salmonella enterica serovar typhi and $S$. enterica serovar paratyphi $A$ isolated from patients in Japan. Antimicrobial Agents and Chemotherapy. 45(3), 956958.

Hutwagner, L. C., Maloney, E. K., Bean, N. H., Slutsker, L. \& Martin, S. M. (1997). Using laboratory-based surveillance data for prevention: an algorithm for detecting Salmonella outbreaks. Emerging Infectious Disease. 3, 395-400.

Kariuki, S., Revathi, G., Muyodi, J., Mwitura, J., Munyalo, A., Mirza, S., \& Hart, C.A. (2004). Characterization of multidrugresistant typhoid in Kenya. Journal of Clinical Microbiology. 42, 1477-1482.

Liza, R. N. \& Annette, K. E. (2004). Age-Stratified Validation of an Indirect Salmonella Dublin Serum Enzyme-Linked Immunosorbent Assay for Individual Diagnosis in Cattle. Journal of Veterinary Diagnostic Investigation. 16, 212

Mead, P. S., Slutsker, L., Dietz, V., McCaig, L. F., Bresee, J. S., Shapiro, C., Griffin, P. M. \& Tauxe R. B. (1999). Food-related 
illness and death in the United States. Emerging Infectious Disease. 5, 607-625.

Mills-Robertson, F., Addy, M. E., Mensah, P. \& Crupper, S. S. (2002). Molecular characterization of antibiotic resistance in clinical Salmonella Typhi isolated in Ghana. FEMS Microbiology Letters. 215(2), 249-253.

Milnes, A. S., Stewart, I., Clifton-Hadley, F. A., Davies, R. H., Newell, D. G., Sayers, A. R., Cheasty, T., Cassar, C., Ridley, A., Cook, A. J. \& Evans, S. J. (2007). Intestinal carriage of verocytotoxigenic Escherichia coli O157, Salmonella, thermophilic Campylobacter and Yersinia enterocolitica, in cattle, sheep and pigs at slaughter in Great Britain during 2003. Epidemiology of Infection. 136, 739-751.

Nielsen, J. (2003). Salmonella Dublin in cattle; use of diagnostic tests for investigation of risk factors and infection dynamics. PhD Thesis. The Royal Veterinary and Agricultural University, London, Pp. 205-218.

Nollet, N., \& Maes, D. (2005). Discrepancies between the Isolation of Salmonella from Mesenteric Lymph Nodes and the Result of Serological Screening in Slaughter Pigs. Veterinary Research. Pp. 544-555.

Pritchard, D. G. (1982). Social and Management Factor involved in Respiratory Disease of Calves. Applied Animal Ethnology. Pp. 198-199.

Shilangale, R. P. (2014). Prevalence, Serotypes and Antimicrobial Resistance of Salmonella Isolated from Beef and Animal Feeds in Namibia. PhD Thesis, University of Namibia.
Wray C., Davies, R. H. (2000). Salmonella infections in cattle. In: Salmonella in domestic animals, ed. Wray, C., Wray, A., 1st ed., CABI Publishing. New York. Pp.169-190.

Hoorfar, J., Wedderkopp, A., \& Lind, P. (1997). Detection of antibodies to Salmonella lipopolysaccharide in muscle fluid from cattle. American Journal of Veterinary Research, 58, 334-337.

Kradel, D. C. \& Miller, W. L. (1991). Salmonella Enteritidis observations on field related problems. Proceedings of 40th Western Poultry Disease Conference. 24-27 April 1991, Acapulco, Guerrero, Mexico, Pp. 146-147.

Ludewig, M., \& Fehlhaber, K. (2001). Prevalence of Salmonella in the pork production chain in the Federal State of Sachsen. 2: Serological investigation of slaughtered animals. Fleischwirtschaft, 81, 96-98.

Wiuff, C., Thorberg, B. M., Engvall, A. \& Lind, P. (2002). Immunochemical analyses of serum antibodies from pig herds in a Salmonella non-endemic region. Veterinary Microbiology. 85, 69-82.

Waldvogel, F. A. (2000): Staphylococcus aureus (including staphylococcal toxic shock) In: Principles and practice of infectious diseases (Mandell, G.L., Bennett, J.L. \& Dolin, R. eds.) Churchill and Livingstone, New York. Pp. 2069-2100. 